\title{
TeChNo Studies: ÄsthetIK UND Geschichte ElEKTRONISCHER TANZMUSIK Kim Feser and Matthias Pasdzierny (eds.)
}

Berlin: b_books, 2016.

ISBN: 978-3-942214-25-4

RRP: EUR20.00

<http://dx.doi.org/10.12801/1947-5403.2017.09.01.05>

\section{TIMOR KAUL}

University of Cologne (Germany)

In 1995 a group of authors who were deeply embedded in the new music scene wrote and published Techno (Anz and Walder 1995), a compendium exploring both the history of the genre in its broader sense as well as its contemporary status. Techno Studies: Ästhetik und Geschichte Elektronischer Tanzmusik adapts not only the cover art of Techno but also its inherently methodological approach, combining various kinds of texts and perspectives on the subject. DJ, writer and editor of scene magazine De:Bug, Sascha Kösch contributes to both anthologies. In Techno Studies, he writes three short essays concerning the practical and epistemological problems of writing reviews of techno tracks.

Daniel Schneider's chapter "Party im Schuber" indicates the process of historicisation and cannonisation of that which was, for a long time, considered inherently futuristic. Schneider, who is based at Archiv der Jugendkulturen in Berlin, highlights the connection between his work as an archivist and the techno scene itself, striving towards a neutral position that takes into account various factions within the scene, as well as the importance of diverse sources of information for a complete, critical research of techno (92). His ideas seem to amalgamate well with the general approach taken in Techno Studies.

The academic study of techno of various disciplines along with its social, cultural and bodily phenomena might be subsumed under the term Electronic Dance Music Culture Studies (EDMCs) and is linked to a "practice shift" in humanities, as Rosa Reitsamer points out in "Die Praxis des Techno". Participant observation or even going native present the opportunity to collect very rich data, including intimate, internal knowledge of subcultural music scenes. However, such personal engagement may cause ethical conflicts as well as

Dancecult: Journal of Electronic Dance Music Culture 9(1) 2017: 90-104 ISSN 1947-5403 @2017 Dancecult http://dj.dancecult.net

\section{dsincecult}


methodological complications, which is one of the classic dilemmas of sociological and ethnographical research. In his chapter "Anonym, verkörpert, anders" Luis-Manuel Garcia, along with the help of four interviewees, describes some of the more intense problems encountered while carrying out ethnographic fieldwork within queer nightlife scenes, where sexual subjectivity and physical safety are often underlying issues. Moreover, the club environment seems to allow for new methods of research to be implemented.

In her chapter "We Call It Techno!" Julia Keilbach reflects on a documentary of the same name, which attempts to reconstruct the birth of techno in Berlin through a montage of short interview samples with pioneers of the scene. However, it is exactly this technique that renders the documentary unable to explore the necessary methodical scope that can be considered to be real oral history; there lies a "hidden author" behind the narrative that is provided to the audience, illustrated through the director's choice of particular statements and sentiments (97). The end result is a historical narrative that excludes the integral role of both gay subculture and the international artists and projects involved in the formation of techno.

In his excellent chapter "Das Nachkriegstrauma abgetanzt?", Matthias Pasdzierny investigates how techno managed to achieve its status as "Soundtrack of the German Reunion". He explains how, in actuality, this process took place retrospectively-the memories of scene members seem to have been affected by media reports that interpreted the new sounds and hedonistic movement as indicative of a "Vergangenheitsbewältigung", a farewell to the old Germany and its Nazi past, and presenting the opportunity to cultivate a completely new German identity (115).

Besides trance, another subgenre of techno-minimal-could take on a special German resonance and image. This development, along with new discourses around minimal as a genre prefix as well as an aesthetic paradigm for any kind of electronic dance music, are analysed by Sean Nye in his chapter "Von Berlin Minimal zu Maximal EDM". The film Fraktus (Germany 2012) portrays an obviously faked techno-myth, placing its origin within the context of the Neue Deutsche Welle (NDW). Despite the fictional characters in the film, its overall argument can be backed up with some evidence-at least when observed from a modern perspective-as mentioned during the talk with musicians Jacques Palminger and Carsten Meyer, aka Erobique, in "Fraktus - ein Techno-Mythos" (139).

In "Klangzeitgeschehen", Barbara Volkwein describes her musicological approach to techno. As a consequence of the methodological difficulties involved in analysing techno tracks, she suggests a combination of traditional and new methods including participant observation, and descriptions of sounds and aural textures. In the case of the latter, Jens Gerrit Papenburg refers to the importance of sound systems and other technical aspects, such as the cutting of maxi singles for reproduction and perception-but also the production of dance music - in his chapter "Boomende Bässe der Disco- und Clubkultur". He convincingly argues that traditional musicological analysis is not able to grasp the bodily aspects of sounds experienced in the club and therefore misses a central aspect of the specific aesthetics this genre of music emits (195). 
Kim Feser recognises another technical aspect of the production of electronic music that has had an immense impact on its aesthetics-sequencers. In his chapter "Ein Sequenzer kommt selten allein", he shows how electronic devices like Moog synthesizers, the Roland 808 and especially a combination of the two might blur existing differentiations between instruments and machines, musicians, composition and automatic processes, as well as between digital software and analogue hardware. Techno-related styles are characterised by the complex interplay between technical innovation, aesthetic discourses and musical practices (235) that include a "false" use of gear (232). This approach should be called experimental, which is something that becomes evident in Stefan Goldmann's chapter "Kreuzmodulation” (162). Goldmann begins with an interesting attempt at developing the aesthetics of techno, which is based on the aural perception of musical material itself, created with specific line-ups of electronic instruments manipulated by filters, effects and FM-synthesis.

While Goldmann refers to the theoretical concept of neuronal learning, Martha Brech again draws on the familiar connection between techno and the poststructuralist philosophy of Gilles Deleuze and Felix Guattari in "Zwischen den Ohren", most evident in releases from the label Mille Plateaux. This kind of highly conceptualised "intelligent" techno and the intellectual reflections on its "deterritorializing" effect had its heyday during the second half of the 1990s. However, deterritorialization might today be found in genres such as glitch hop-following developments in this area would likely be a much more interesting focus for contemporary research.

In "Vom Ereignis erzählen", Diedrich Diederichsen refers to the frequently assumed countercultural dimension of techno and argues that the music's immediate bodily experience is in line with the non-political aspects of the foregone hippy movement (62). The question of "meaning" in often instrumental techno tracks is evaluated by Jochen Bonz in "Am Nullpunkt der Identifikation". Opposing the ideas inspired by poststructuralist perspectives of alternative identifications for the individual and one's liberation via techno, Bonz claims that the expressive culture of techno is characterized by weak and often shortlived forms of identification, which correspond with the semantic and semiotic openness or even meaningless of the music itself (47).

One might argue against Bonz's view that many people deeply identify with certain techno labels, artists or tracks, as is often the case with many other genres of music. The idea that techno is the not-too-distant-cousin of other forms of pop emerges again while reading Techno Studies and it raises its head once more in the chapter "Kommunikative Strategien und Ideologien von Liveness bei Laptop Performances”, musicologist Mark Butler exploring how the famous issue of "authenticity" was revived by DJ performances. Rosa Reitsamer goes on to show that physicality is as much a part of the DJ's subcultural capital as both their musical selection and knowledge. The resulting scene hierarchies, which are often linked with categories such as gender or race, have to be seen critically (32).

Today's "techno ideologies" and idealized historical narratives often seem to result from not too much more than a series of events that usually begin with the politicallydriven ideals of influencers, spread by scene media and eventually being picked up on and 
backed up by some academic analysts afterwards. Furthermore, it is still all too common that the Afro-American roots of the genre are ignored (or even "whitewashed"), causing further misinterpretation. In light of its Afro-American heritage, characteristics particular to techno, such as pattern repetition or extensive sound manipulation, appear as neither the mere results of new technical possibilities nor as a sudden break in musical or cultural history, but as central stylistic devices to be found in various other genres like rhythm ' $\mathrm{n}$ ' blues, funk, disco or hip-hop. However, despite these general critical remarks, Techno Studies surely provides some immensely important and critical contributions to the discourses surrounding the field at large, whether that be as subsumed under the umbrella term techno or under today's more popular term EDM.

\section{REFERENCES}

Anz, Philipp and Patrick Walder (eds.). 1995. Techno. Hamburg: Rowohlt.

\section{Hip-Hop Headphones: A Scholar's Critical Playlist JAMES B. PETERSON}

New York: Bloomsbury Academic, 2016. ISBN: 978-1-5013-0825-3 (hardcover), 978-1-5013-0824-6 (paperback), 978-1-5013-0827-7 (EPUB e-book), 978-1-5013-0826-0 (PDF e-book) RRP: US\$120.00 (hardcover), US\$29.95 (paperback), US\$25.99 (EPUB e-book), US\$25.99 (PDF e-book)

$<\underline{\text { http://dx.doi.org/10.12801/1947-5403.2017.09.01.06 }>}$

\section{JAMES COX}

UNIVERSITY OF QUEENSLAND (AUSTRALIA)

By his own admission, James Braxton Peterson is "one of the earlier professors to teach Hip-Hop at the collegiate level", and Hip-Hop Headphones is a great representation of Peterson's $20+$ years of engagement with hip-hop at this scholarly level. Hip-hop studies have been conducted by scholars in a variety of different disciplines-geographers, linguists, sociologists, anthropologists and many others have all made invaluable contributions. Peterson himself comes to hip-hop studies as a Professor of English and Director of Africana studies at Lehigh University. With this diversity in mind, Hip-Hop Headphones sets out some very useful approaches to the study of hip-hop culture. 
Hip-Hop Headphones is a collection of definitions, lectures, academic essays and other scholarly discussions and resources all produced by Peterson. The book is organised into five parts: the first examines definitions; the second looks at speech and beats; the third comprises a collection of scholarly reviews; the fourth is a transcription of a round-table discussion on race theory and gender in hip-hop's global future; and the final section is titled "Rapademics" which includes pieces Peterson has written in response to his role as a public academic in the US.

The collected nature of the book is part of its strength, but also its greatest weakness. The collection of works here demonstrates the scope of engagement possible in hip-hop studies. However, the book does feel like it often repeats itself-in particular, examples and points that, when the book is read as a whole, make the reader feel like we've been there before. Some of the inclusions in the collection also let down the strength of the book-the scholarly reviews of books, documentaries and articles do not add as much to the collection as they could. These are the only real weaknesses in the book though, as Hip-Hop Headphones provides some valuable contributions to the field of hip-hop studies, particularly in setting out definitions and methodologies for not only researching hip-hop culture but also teaching it in a variety of settings.

Peterson's emphasis on "critical listening" to a range of hip-hop related texts sets up a key theme that is continued throughout the book. The first chapter, "Re: Definition", is one of the strongest of the book and would be very useful as a reading for students and educators alike who are not necessarily familiar with hip-hop studies or hip-hop culture itself. As the title suggests, the chapter establishes some very useful definitions of hip-hop culture and for the study of hip-hop, such as Peterson's definition of the three loosely organized eras of hip-hop. Within hip-hop scholarship there has generally been a reluctance and "hedgingof-bets" when it comes to providing definitive years for the eras of hip-hop. Peterson defines the "Old School Era" (1979-1987), followed by the "Golden Age Era" (1987-1993) and the "Platinum Era" (1994-approximately 2004). While I'm not personally sold on the choice of "Platinum Era" as a term, these definitions do provide a welcome addition to hip-hop scholarship.

While the first chapter would work well as a reading for undergraduate students, the second chapter is probably better suited to post-graduates and educators who are teaching aspects of hip-hop culture. Within this chapter Peterson presents a rubric for appreciating, evaluating and understanding the impact and importance of MCs. While the elements of the rubric are similar to many hip-hop fans' discussions around questions like "who's your favourite rapper", it provides more structure to these discussions. The rubric is also an example of the "critical listening" approach Peterson promotes throughout the book. In this way, by critically listening to an artist's work, and applying such a rubric, conversations about "favourites" and "bests" become conversations about aesthetics, location and performance. This combination of critical thinking and listening is an important way of shaping in-class discussions of hip-hop. 
The most valuable parts of the book are perhaps found in the appendices, where Peterson provides examples of the syllabi he has used to teach a variety of hip-hop inspired courses, and also a collection of playlists he has assembled during these classes. These appendices relate specifically to chapters two and four in the book, and are excellent examples of how hip-hop cultural practices can be incorporated into classroom pedagogies. Peterson advances what he calls a "Playlist Pedagogy", and he ties this in with the concept of the "ubiquitous learning environment". Suggested by Yahya, Ahmad and Jalil (2010), ubiquitous learning environments are described as "any setting in which students can become totally immersed in the learning process". Peterson uses playlists here, in combination with the aforementioned critical listening skills, as a way to extend the potential for learning beyond the traditional classroom space. The playlists described in the appendix cover all manner of topics raised in hip-hop songs, such as suicide, black prison narratives, often-sampled songs, and odes to/of hip-hop culture. These playlists are just suggestions and ones that Peterson has complied through his experience using them in classrooms, but they also make great starting resources for those teaching with and about hip-hop.

Hip-Hop Headphones makes a valuable, and much needed, contribution to the field of hip-hop studies. Chapters from the book would be excellent readings for students, but the book's main audience will be those interested in using hip-hop in classrooms. The strongest sections of the book are where Peterson documents his teaching practices, and these sections will be incredibly useful to those teaching elements of hip-hop culture.

\section{REFERENCES}

Yahya, Saadiah, Erny Arniza Ahmad and Kamarularifin Abd Jalil. 2010. "The Definition and Characteristics of Ubiquitous Learning: A Discussion”. International Journal of Education and Development using Information and Communication Technology 6(1): 117-27. 


\section{An Introduction to Music TeChnology, Second Edition DAN HOSKEN}

New York: Routledge, 2015.

ISBN: 978-0-415-82572-6 (hardcover), 978-0-415-82573-3 (paperback)

RRP: US\$147.00 (hardcover), US\$68.95 (paperback)

$<\underline{\text { http://dx.doi.org/10.12801/1947-5403.2017.09.01.07> }}$

MARTIN K. KosZOLKo

Melbourne Polytechnic (Australia)

Dan Hosken explores the myriad of ways in which technology can be implemented in the practices of composers, performers and teachers. This introductory text spans a large group of topics covered in a comprehensive and accessible way. The volume is divided into four sections: Sound, Audio, MIDI and Software Instruments and Computer Notation and Computer-Assisted Instruction. Included are also two appendices, covering Computer Hardware and Computer Software. Each of the main sections is preceded by an overview text summarising the key issues discussed.

Hosken argues that principles of music technology should be analysed in the context of practical work, and throughout the text he provides suggested activities, complementing the core content. The importance of aural experiences is also emphasised and the book is presented with a companion website featuring audio examples relevant to the covered topics. The website is up to date and provides a large collection of resources, such as audio examples, YouTube videos and URLs to relevant online content. The online component is a helpful expansion of the material covered in the book and allows dissemination of various types of information conveniently gathered in one place, which is practical in a teaching environment.

Hosken is pragmatic in his approach and prioritises the importance of the presented material to students operating in the contemporary music production landscape. An example of this method is the choice of topics for the appendices. The decision to include the discussion on computer hardware and software in the appendices was dictated by the fact that, while important, these topics are intuitively understood by current generations of students who grew up with computer technologies. While a good understanding of the fundamental knowledge related to computer hardware and software is very helpful in troubleshooting of the technical problems as well as the efficient day-to-day work with music technology, the priority in the volume is given to sound-related topics, which is a sensible choice.

The second edition of the book, reviewed here, sees a restructure of some of the content as well as new additions. Section three MIDI and Software Instruments now includes chapters on synthesis and sampling, which in the first edition of the book were presented 
separately. The new edition offers several references to mobile platforms, particularly iOS-based apps facilitating music creation and performance as well as computer-assisted instruction. This discussion on mobile apps is a welcome update, as since the launch of the iOS App Store in 2008 musicians have gained access to an ever-growing range of tactile apps with unparalleled music capabilities. In addition to the information on iOS apps, the updated text features references to hardware accessories relevant to the iOS platform.

The book helps to facilitate an understanding of the key principles that lie behind the technology, rather than discussing specific software or hardware tools. While the text does not focus on specific software there are numerous references to popular plugins and digital audio workstation (DAW) programs. These examples offer a fairly broad overview of available software options, with the most frequently mentioned DAW applications being Pro Tools, Reason and Logic Pro, while other popular DAWs such as Cubase and Ableton are mentioned only in passing. This approach helps to avoid the dangers of analysing minute details of technological tools that change at a rapid pace, which would quickly render such analysis obsolete. As such, there is a degree of reliance on the reader's capacity to conduct further research into various, more specific aspects of audio technology that they might be utilising or learning at the same time. This additional research can hopefully be facilitated and aided by lecturers of undergraduate courses, as students are Hosken's primary reader group. In my own tertiary teaching practice, I found the segments of the book discussing the properties of sound, MIDI, synthesis, sampling and bit rates to be of particular value to students new to these aspects of music technology. Such content has proven to be an excellent resource for introductory information on these topics.

The book is designed for makers and creators who want to use technology in their present or future professional activities and for whom, Hosken argues, it is important to understand how music technology works. He does not discuss technology separate to music, which, I believe, is a step than can help practitioners who frequently wear a hat of musician and sound technician at the same time. In my practice as a music producer I found that it is often easy to fall into the trappings of technological solutions to problems encountered in a mix and forget about the musical ones. An example of a discussion just as important to music performers as it should be to music technologists is Chapter Three, featured in the first section of the book focused on Sound, where topics such as harmonics, overtones and timbre modification are discussed.

A limitation of the book is the lack of more in-depth explanation of some complex topics or processes that might be challenging for beginners. Examples of such topics, covered rather briefly, include a discussion on tuning and temperament in the section on Sound, and the description of compression in the section covering Audio. A topic that could be also expanded in a future update to the section on MIDI and Software Instruments is elaboration on how MIDI technology and computer software can be used in a live performance context. The closest the book gets to this issue is a discussion on performance apps for iOS devices and a brief description of MIDI mapping. Yet there is no discussion on the possibilities for interactive performance facilitated by programs such as Ableton Live. This software is discussed primarily as an example of a DAW capable of hosting Max 
for Live, where the latter is mentioned as an illustration of a programming environment. It is possible, however, to use other featured topics on MIDI hardware and iOS performance apps as a helpful guide covering at least some issues related to live performance set-ups. At the beginning of the book, Hosken clearly states that the amount and depth of coverage was carefully considered and designed in a way to make the content suitable for an introductory class. To combat the issue of limited coverage of some of the more complex issues, at the end of each of the sections we find a list of further readings as well as suggested activities, expanding on the initial topics.

The overarching thesis of Hosken's book is that the understanding and mastering of technology empowers musicians to focus on music and ultimately provides them with the means of making a living in a variety of ways, such as arranging, composing, teaching and performing. This is aligned with my own experience, as I found that the merging of strong musical skills with an in-depth knowledge of technology is a reliable recipe for being able to gain independence as well as authority in the studio, on stage as well as in the music technology classroom. Overall, Hosken has successfully analysed and presented a wide breadth of material that is of importance to music practitioners utilising technology. The book is a comprehensive introductory resource on a variety of topics that can be used as a valuable starting point to further investigations in the field.

\section{LOW END THEORY: BASS, BODIES AND THE MATERIALITY OF SONIC EXPERIENCE} Paul C. Jasen

London: Bloomsbury Academic, 2016.

ISBN: 978-1-5013-0993-9 (hardcover), 978-1-5013-3591-4 (paperback), 978-1-5013-0995-3 (EPUB e-book), 978-1-5013-0994-6 (PDF e-book)

RRP: US\$120.00 (hardcover), US\$39.95 (paperback), US\$34.99 (EPUB e-book), US\$34.99 (PDF e-book)

$<\underline{\text { http://dx.doi.org/10.12801/1947-5403.2017.09.01.08> }}$

DANIEL SCHNEE

INDEPENDENT SCHOLAR (CANADA)

Decades ago, a volunteer at the Edmonton Jazz Festival was assigned driving duties for pianist Herman Poole Blount, to transport he and members of his group between Calgary and Edmonton for their respective festivals. A three-hour journey, Blount spent much of the time scribbling in a small black notebook, often pausing to think and look out the window. The volunteer was extremely curious about the contents of the book, and made it his mission 
to peak inside of it at any given opportunity. During a brief pause at a gas station to refuel, the band exited to buy snacks, presenting the driver with his opportunity. It turned out to be a small collection of crossword puzzles. But why was the driver obsessed with Blount's book? The answer to this true story (told to me personally by the driver himself) can be found in Low End Theory: Bass, Bodies and the Materiality of Sonic Experience by Paul C. Jasen.

Low End Theory is a fascinating study of low frequency pitches, their physical effects, and how humans understand and define such tones, the goal being the creation of new language and terminology that helps the humanities better appreciate material agencies as sound-related scholarship moves into unexplored areas. What is there to be discovered in low tones? Is it possible to create a new, previously non-existent language to access and create cross-cultural comparisons?

The book starts with the idea that there is not a suitable language to access and describe the cross-cultural investigations of bass tone, how things feel and sound in settings where there is a significant amount of low tone. Using the general term "bass", this word also includes or represents vibration, and extra cochlear perception including acoustics, infrasound and liminal events that could be called sound-like, pointing to "whole intermodal worlds of sonic experience beyond audition, where perception is unsettled and synesthetic overlaps make bodies re-imagine themselves and their surroundings" (3). Sound (as a mechanical vibration) is thus best understood as a relation and not an object. Thinking with vibration then requires conceptual tools that are especially attuned to matter-in-process and what Jasen calls the "circuits of responsivity that emerge between sonorous beings" (14).

A key theoretical concept underlying the book is the idea that the human body in its materiality is a contingent being adaptively recomposing (moving, adjusting, testing, imagining, anticipating) in the immanent relations of its worldly encounters. Adding sound into the mix, we arrive at an incorporeal materialism, a body's relational potentials (which theorist Brian Massumi describes as their "yet-ness": 13). This contingent, imaginative "body" that emerges in its sonorous relations is what Jasen calls the "sonic body": wondering how a "given vibratory milieu augments or diminishes" a body's capacity to act-alone or collectively (194). By imagining or theorizing this sonic body Jasen asks not what do we make of bass, but rather what does bass make of us? How does bass undulate and unsettle; how does it incite; how does it invade the lives of people, drawing bodily thought into new equations with itself and its surroundings?

Two important concepts that Jasen focuses on is how sound, in this context, is most meaningfully understood as (1) a relation and not an object, and (2) the foundation of what is known as a myth science: the unmaking of consensual reality and inventing livable futures through myth making; the affect of sonic experience being a modulatory influence on the social scenes in which low (or indeed any) tones occur. Also including infrasound, or inaudible frequencies from nature or industry (the "presence-absence" of such sounds), low tones register in the body as a feeling of being acted upon by an unseen agent, which stimulates imagination and influences perceived reality. Here Jasen introduces the term spectral catalysis, topologies of wave energies or conditions of molecularity that open 
up the body to "strange minglings" aka spectral-level events or the swarming of spectral uncertainties that create (1) new inflections of felt reality, and (2) turn the body into a series of questions and forced adaptations (33). This is essentially how "certain materialsonic conditions can deterritorialize the sonic body in ways that spark new trajectories in individual and collective activities" (17), adding to the myth-sciencing that can occur in such moments.

One such myth-scientist is the aforementioned pianist Herman Blount, and the effect of his mythology on his fans. Blount (1914-1993) was a Philadelphia-based jazz pianist, born and raised in Alabama. Though this is fact, Blount changed his named to "Sun Ra" and vehemently insisted that he was born and raised on the planet Saturn, later coming to Earth to create peace and harmony through poetry, onstage theatrics, unusual electric instruments such as his massive hexagonal light instrument dubbed the "Outerspace Visual Communicator", and the making of cosmic music. His efforts would later come under the aesthetic category of Afrofuturism: an African-American movement combining science fiction, mythology, philosophy, fantasy and social critique, the "application of imaginative force to the alteration of lived reality" with which African Americans might invent their own "Alter Destiny" (200). As Ra himself states, "myth permits man to situate himself with the past and the future. What I am looking for are the myths of the future, the destiny of man ... if one wants to act on the destiny of the world, it's necessary to treat it like a myth" (Lock 1999: 61). Ra's myth-science itself was highly influential and immense, drawing upon ancient hermetic writing, religious texts, theosophy, contemporary science fiction and cryptic numerology, and was instrumental in reviving African-American interest in ancient Egypt. Ra even called his various assembled sidemen "tone scientists".

Such was the mystique and legend surrounding Ra that the aforementioned jazz festival driver was immensely interested in peaking into Ra's black notebook to see if there was anything of philosophical or literary importance, any arcana he could glean and share with his friends: wisdom or creative mythology that would give the driver social capital amongst his peers (status via participation in the Ra mythos through personal contact with the master myth-scientist himself). As Jasen reveals, bodies of myth science accumulate around unusual vibratory milieus (28), and Sun Ra's own "tale of becoming", how he categorized and philosophized about his experiential knowledge, serves as an excellent parergon to Jasen's own attempt at rigorous speculation on the sound body.

Thus, not meaning to be definitive, Jasen intends for the book to be an "experiment" (187), its own kind of myth science, a work that "strives instead to engender a mode of thought that draws sound-related scholarship into unfamiliar territory, and help nudge the humanities more broadly towards a greater appreciation of material agencies" (19). The aim is "to fertilize a mode of perception-to find ways of conceptually inhabiting the vibratory encounter, finding means to render it sensible in language, and letting theory be informed by it" (187). Jasen also states that his writing, like a myth-science, "need not be utterly 'right' or objectively accurate. It's doing its job if it manages to convey something of a milieu's affects, and their escapes, in ways that put theory more closely in touch with the sonic body" (17). Indeed, as Hakim Williams states, the "quest for certainty" in the sciences "ends up narrowing and 
'colonizing' the realm of the possibilities, in terms of diversity of approaches, and ways of being and thinking" (2015: 28). This is the great strength of the book and ultimately the success of its goal, as it analyzes a wide variety of sonic events and their sites in thoughtful and imaginative ways while attempting to evade scientific monism or intrinsicism.

But this also raises the issue that myth "science" provides no guarantee that any/all mythologies will avoid inculcating actual delusion, cult behaviour, oppression, or other modes of thought and action that are intellectually suspect, or obscure social reality. Jasen openly admits his work is an effort to "deform" thought, rather than clarify it, to "push it into the always complex, and often strange, traffic between nature and culture" (17). If we have to deform thought to advance, then this suggests Jasen's method neither enriches nor supplements the existing scholarship on sound and materiality. Jasen also states that the scientific literature on sound, and its accounts of peculiar neuro-scientific effects, is "constrained by its unwillingness to pursue anomaly and its social life" (17), though he cites no examples of such. This weakens his argument and, as Alan Singer states, "the disposition towards contextual relativism depends on prejudicially conflating reason with instrumental dogmatic thinking. In this way, reason becomes the scapegoat antagonist for without which any such aesthetic quest cannot proceed to the sanctifying pedestal of pure art. The conflict between reason and the aesthetic becomes the motive for the aesthetic evasion of conflict" (2003: 111-12).

Jasen concludes the book with the statement that "we will never know just what a sonic body can do. All the more reason to keep asking the question" (194). Following such a declarative statement with the inference that we should ignore its premise (the "certainty" of never knowing) works to undermine the salient aspects of the book and feels like a negation of Jasen's previous efforts, the very monism he seeks to avoid. In that sense, Salomé Voegelin's book Sonic Possible Worlds: Hearing the Continuum of Sound (2014) works better towards categorizing or defining theory around what is heard and felt, versus what we imagine has been heard and felt, through descriptive language she defines as "textual phonography" (2014: 1). Overall, though, Low End Theory is an interesting and thoughtful addition to the greater discussion of sound materiality, and will serve as excellent graduatelevel reading for ethnomusicologists, folklorists and anthropologists alike.

\section{REFERENCES}

Lock, Graham. 1999. Blutopia: Visions of the Future and Revisions of the Past in the Work of Sun Ra, Duke Ellington, and Anthony Braxton. Durham: Duke University Press.

Singer, Alan. 2003. Aesthetic Reason: Artworks and the Deliberative Ethos. University Park: Pennsylvania State University Press.

Voegelin, Salomé. 2014. Sonic Possible Worlds: Hearing the Continuum of Sound. New York: Bloomsbury Academic.

Williams, Hakim M.A. 2015. "Fighting a Resurgent Hyper-Positivism in Education is Music to My Ears". Action, Criticism, and Theory for Music Education 14(1): 19-43. 


\section{Digital Arts: An Introduction to New Media CAT HOPE AND JOHN RYAN}

London: Bloomsbury, 2014.

ISBN: 978-1-7809-3320-7 (hardcover), 978-1-7809-3323-8 (paperback), 978-1-7809-3321-4 (EPUB

e-book), 978-1-7809-3329-0 (PDF e-book)

RRP: $£ 80.00$ (hardcover), 223.99 (paperback), £20.99 (EPUB e-book), 20.99 (PDF e-book)

$<\underline{\text { http://dx.doi.org/10.12801/1947-5403.2017.09.01.09> }}$

\section{TOBY YOUNG}

UNIVERSITY OF OXFORD (UK)

Digital Arts is a joint effort from Australian scholars Cat Hope (a composer, whose work I've admired from afar for a while) and John Ryan, and is presented very much as an introductory reader to some of the central theoretical and practical issues surrounding new media art. The overall narrative thread-if one can call it that —of the book's nine chapters is one of humanising; tracing a historico-cultural journey from digital art's inception in the 20 th century towards its impact on both the art world and broader society.

Throughout the book, Hope and Ryan forge a delicate path between the need for taxonomy and clarity (it being a textbook, after all) and the more ephemeral and open discussions needed for such a mobile and trans-disciplinary topic. The opening chapter in particular is a stroke of genius in this respect, presenting the context of digital art as a cartography-a brilliant alternative to either the repertoire-based canonic approach taken by Cox and Warner (2004) or the techno-centric focus of Demers (2010). This mapping of the various historical and aesthetic points which make up the various networks of ideology, theory and practice that define digital arts is impressive not least in its breadth but also its depth, demonstrating clearly yet efficiently-the book is only 218 pages long-how such communities of thought came to be. The balance between mapping a broad field whilst providing concrete examples (in handy little boxes) and reflecting on some of the related key debates, both inside and outside the field, is a central concern throughout the book, and on the whole is achieved successfully, even if the authors' conclusion that this complexity makes digital arts as a genre impossible to define (3) feels a little easy.

Through the main body of the book, Hope and Ryan unfold a methodical examination of the "digital effect" on key areas of artistic endeavour: photography and film (chapter 3), theatre and dance (chapter 4), music (chapter 5), and finally the sui generis medium of digital web art (chapter 5); all underpinned by a series of helpful case studies on specific artworks, with accompanying mock essay questions masquerading as "reflections". The fifth chapter on digital music will probably be of most interest to readers here. Passing by the obvious theoretical starting point of Benjamin (Hope and Ryan use his seminal "The Work of Art 
in the Age of Mechanical Reproduction" as the basis for their discussion of photography instead), this chapter is framed around the relationship between technological advancement, genre expansion and-by proxy - the expansion of musical scenes that these new forms of digital production and consumption create. Their opening section of background traces this "drastic change ... [in] the direction of music" (104) back to serialism, via musique concrète, of course, before moving through a heavy discussion of the nature of digital synthesis into a light one on some of the tools of digital music production and compositional practices associated with electronic music.

Whilst readers of this review are guaranteed to know their digital audio workstations from their digital interfaces, I can see how such a basic introduction would be useful to students, nicely peppered as it is with nods to the changing nature of creative processes that these technologies foster. An unfortunately brief discussion of liveness in electronic music - it doesn't even include the obligatory line about DJs checking their emails! - leads to possibly the most compelling section of the chapter, discussing the aesthetic issues of digitally-created music and the interesting tension between its presence in both experimental art and popular culture. Maybe in a future publication or revision of this book, Hope and Ryan might consider extending this section even further, perhaps considering some of the social relationships these art practices form commentaries to (for example noise art as a critical reaction to technological acceleration) or the new move in electronic sound art towards an engagement with the post-human (in works such as Guy Ben-Ary's cellF, which uses a biological neural network growing in a Petri dish to control an array of analogue modular synthesizers in order to create a "neural synthesiser").

The book's concluding chapters focus on distribution practices, including discussions of downloading, file-sharing and creative commons (chapter 7), and archival preservation of digital material (chapter 8). Whilst these are some of the most prosaic topics of the project, the concluding chapter (9) is a particular highlight, replete with a rich discussion of the political and ethical dimensions of digital arts and the role of social media (including non-traditional networked environments like online gaming) in the interface that digital practices offer between the artistic and social. Looking back a few years after the publication of this book, it is clear that this is one of the most important issues facing digital arts: that of the role art can play as a catalyst in creating the prerequisite conditions necessary to enable social innovation and change, breaking down barriers and opening up a new potential way to democratize the arts (157).

After the cartographic gestures of the introduction, these latter chapters feel more like Deleuzian tracing, gathering together ideas on a teleological journey towards an alluring sense of completeness, than cartography. Given the spiralling of this book towards a final concluding chapter on hyperrealism in digital art, this movement from mapping to tracing seems to be no coincidence, perhaps presenting a subtle meta-critique of the relationship between the fluid nature of digital arts and the pedagogical need to linearize a field which is still very much a boundary-less network space (pace Latour), perhaps even a vulnerable space loosely encompassing a group of discrete disciplines with shared processes but not necessarily goals. 
Or perhaps I'm just over-reading it. For all of the tempting allusions to meta-narratives and subtext, the best way I can summarize this book is functional. In general, the language and presentation of ideas is clear, with the exception of a few slightly obfuscated turns of phrase, such as (for example) the claim that digital art is the "ubiquitous part of our vernacular in today's ever more globalized world" (2). Nevertheless, the central themes Hope and Ryan draw on are extremely well thought through, with useful bullet-point summaries and further reading lists in each chapter providing the backbone to a clear and comprehensive textbook that would sit well at the heart of any university course on digital and new media art. However, whilst there is considerable critical engagement with the material discussed, there is little in the way of the innovation or revelation needed to make this book a real addition to the established body of scholarly material on electronic music. This isn't to diminish the work at all-it is brilliant in its relevance and succinct accessibility, and I would highly recommend it to anyone teaching a new media art course-but I would definitely welcome a more adventurous work from the brilliant duo of Hope and Ryan.

\section{REFERENCES}

Benjamin, Walter. 1977 [1936]. “The Work of Art in the Age of Mechanical Reproduction”. In Illuminations (trans. Harry Zohn). New York: Schocken Books.

Cox, Christoph and Daniel Warner (eds.). 2004. Audio Culture: Readings in Modern Music. London: Continuum.

Demers, Joanna. 2010. Listening Through the Noise: The Aesthetics of Experimental Electronic Music. Oxford: Oxford University Press. 